\title{
The CARE (CAse REport) guidelines and the standardization of case reports
}

\author{
Richard A Rison ${ }^{1 *}$, Michael R Kidd ${ }^{2}$ and Christian A Koch ${ }^{3,4}$
}

\begin{abstract}
Case reports comprise the core of Journal of Medical Case Reports, are a time-honored tradition firmly established within the medical literature, and represent a growing importance of valuable clinical medical information in our modern information-flowing times. While there is already a body of published literature on how and when to write a case report and both Journal of Medical Case Reports and BioMed Central make known their own criteria, case report quality across all of the medical literature is still variable. Additionally, although health reporting agencies do have standardization guidelines for other aspects of health-care reporting, there has never been an organizational body responsible for international standardization of how to write a case report. With the newly-published CARE (CAse REport) guidelines, Gagnier and colleagues hope to change this. This editorial serves as a brief introduction to the CARE guidelines and briefly examines the proposed standardization of case reports. We invite feedback on the CARE guidelines from all of our readers and encourage their trial run implementation by our own case report authors.
\end{abstract}

In the immortal words of the famous Canadian physician, first Professor of Medicine and founder of the Medical Service at Johns Hopkins Hospital, and of course our 'Father of Modern Medicine', William Osler (July 12, 1849 to December 29, 1919):

'Always note and record the unusual...Publish it. Place it on permanent record as a short, concise note. Such communications are always of value.' [1].

But how exactly do we do this? What makes a good case report? While most of us may follow the maxim 'I know it when I see it', few if any have had formal training on what constitutes a good case report and how to write one. We are initially exposed to case reports in our readings during medical training, and many of us write our first ones in residency under the auspices of one of our attending professors. Unlike many other aspects of our medical training, that of writing case reports is not standardized. There is a wide body of published literature on how to construct a case report, including the different sections of a case report (abstract,

\footnotetext{
* Correspondence: rison@usc.edu

'Presbyterian Intercommunity Hospital Health Stroke Program, University of Southern California Keck School of Medicine, Los Angeles County Medical Center, 12401 Washington Boulevard, Whittier, CA 90602, USA

Full list of author information is available at the end of the article
}

introduction, case presentation, and so on) and when to write one $[2,3]$, but different journals have different criteria and case report quality can be variable $[4,5]$.

The consensus-based clinical case report guideline development paper by Gagnier and colleagues now addresses the important issue of standardizing case report formats [6]. The CARE (CAse REport) guidelines consist of a three-phase consensus-based process that involved 27 participants, all of whom have involvement in clinical case report writing and editing (including the authors of this editorial). The process included telephone interviews, a face-to-face meeting and, finally, a refined checklist of 13 items that should comprise a case report. Throughout the entire process, we were all asked what information was required in case-reporting guidelines, the rationale for our suggestions, and references that supported our reasoning. The primary items of the CARE checklist, which should be familiar to our readers, are the following: title, key words, abstract, introduction, patient information, clinical findings, timeline, diagnostic assessment, therapeutic interventions, follow-up and outcomes, discussion, patient perspective, and informed consent. The manuscript provides a useful table displaying the CARE guidelines checklist that authors can easily refer to.

The CARE guidelines have been presented at international conferences and workshops where they have been met with 
enthusiasm. These included the Peer Review and Biomedical Publication Congress in Chicago sponsored by the British Medical Journal and the Journal of the American Medical Association on September 10, 2013, which coincided with simultaneous publication within the following medical journals: BMJ Case Reports, Deutsches Ärzteblatt, Headache, Global Advances in Health and Medicine, Journal of Clinical Epidemiology, Journal of Dietary Supplements and the Journal of Medical Case Reports. Additionally, by involving Journal of Medical Case Reports and BioMed Central (BMC), there will be open-access outreach to the 250 journals depositing case reports into the BMC Cases Database.

As Gagnier and colleagues aptly point out, there are already multiple organizations for health-care reporting agencies including for the following publication types: randomized controlled trials (Consolidated Standards of Reporting Trials, or CONSORT) [7], observational studies (Strengthening the Reporting of Observational studies in Epidemiology, or STROBE) [8], and systematic reviews and meta-analyses (Preferred Reporting Items for Systematic Reviews and Meta-Analyses, or PRISMA) [9]. Guidelines have also been developed for adverse-event case reports [10], and all authors should be familiar with the Committee on Publication Ethics (COPE) [11] and the Enhancing the Quality and Transparency Of Health Research (EQUATOR) Network [12]. Up until the CARE guidelines publication, however, general international reporting guidelines for case reports have not existed.

Readers of Journal of Medical Case Reports (launched by BMC in 2007) recognize the time-honored importance of case reports as a valuable source of new ideas and information in clinical medicine, and there are published editorials available on the continued importance of open-access case reports in our modern information-flowing world [13-15]. When BMC's open-access Cases Database was created in 2012 by author MRK and colleagues, it brought the total number of published case reports to 11,000, from 50 included medical journals. This grew to more than 26,000 case reports from 212 included medical journals within the span of just six months. The data continues to grow: 28,298 peer-reviewed medical case reports from 250 journals upon last check (!) [16]. BMC has also now published personalized advice on how to write a case report for Journal of Medical Case Reports and BMC Research Notes along with an inside look into the editorial process [17].

We hope that the CARE guidelines will provide an international, general, non-journal-specific framework for completeness and transparency for published case reports, striking a balance between adequate detail and concise writing that can be used by all authors for all journals that publish case reports. The CARE guidelines are available on a dedicated website [18] along with the EQUATOR Network website [12], and will be translated into multiple languages. All authors, journal editors and peer reviewers are encouraged to pilot the CARE checklist and provide feedback that can be incorporated into regular updates. Research into the impact of the CARE guidelines on case reporting will also be conducted, and we look forward to a follow-up article showing the impact on clinical case reports. We also invite comments from all BMC case report readers, authors, editors and peer reviewers on what you think and how you feel that the CARE guidelines can be incorporated into not just Journal of Medical Case Reports but all BMC journals that publish case reports, including BMC Research Notes and the rest of the BMC series.

\section{Author details}

${ }^{1}$ Presbyterian Intercommunity Hospital Health Stroke Program, University of Southern California Keck School of Medicine, Los Angeles County Medical Center, 12401 Washington Boulevard, Whittier, CA 90602, USA. 'Faculty of Health Sciences, Flinders University, GPO Box 2100, Adelaide SA 5001, Australia. ${ }^{3}$ Department of Medicine, G. V (Sonny) Montgomery VA Medical Center, Jackson, MS 39216, USA. ${ }^{4}$ Division of Endocrinology, Department of Medicine, University of Mississippi Medical Center, Jackson, MS 39216, USA.

Received: 29 August 2013 Accepted: 31 October 2013

Published: 27 November 2013

\section{References}

1. Thayer WS: Osler, The Teacher Sir William Osler, Bart. Baltimore: Johns Hopkins Press; 1920:51-52.

2. Cohen H: How to write a case report. Am J Health Syst Pharm 2006, 63:1888-1892

3. Carleton HA, Webb ML: The case report in context. Yale J Biol Med 2012, 85:93-96.

4. Kaszkin-Bettag M, Hildebrandt W: Case report on cancer therapies: the urgent need to improve the reporting quality. Global Adv Health Med 2012, 1(2):8-10.

5. Kljakovic M: Single cases in general practice and general medical journals. Aust Fam Physician 2002, 31(7):669-673.

6. Gagnier J, Kienle G, Altman DG, Moher D, Sox H, Riley D, the CARE Group: The CARE guidelines: consensus-based clinical case report guideline development. J Med Case Reports 2013 [Epub ahead of print].

7. Schulz KF, Altman DG, Moher D: CONSORT 2010 statement: updated guidelines for reporting parallel group randomized trials. Ann Intern Med 2010, 152(11):726-732.

8. von Elm E, Altman DG, Egger M, Pocock SJ, Gøtzsche PC, Vandenbroucke JP: STROBE Initiative: The strengthening the reporting of observational studies in epidemiology (STROBE) statement: guidelines for reporting observational studies. BMJ 2007, 335(7624):806-808.

9. Moher D, Liberati A, Tetzlaff J, Altman DG, the PRISMA Group: Preferred reporting items for systematic reviews and meta-analyses: the PRISMA Statement. PLoS Med 2009, 6(7):e1000097.

10. Kelly WN, Arellano FM, Barnes J, Bergman U, Edwards RI, Fernandez AM, Freedman SB, Goldsmith DI, Huang KA, Jones JK, McLeay R, Moore N, Stather RH, Trenque T, Troutman WG, van Puijenbroek E, Williams F, Wise RP: International Society for Pharmacoepidemiology, International Society of Pharmacovigilance: Guidelines for submitting adverse event reports for publication. Drug Saf 2007, 30(5):367-373.

11. COPE: Promoting integrity in research publication. [http://publicationethics. org/]

12. EQUATOR network website. [http://www.equator-network.org]

13. Kidd MR, Saltman DC: Case reports at the vanguard of 21st century medicine. J Med Case Reports 2012, 6:156.

14. Rison RA: Neurology case reporting: a call for all. J Med Case Reports 2011, 5:113. 
15. Cabán-Martinez AJ, Beltrán WF: Advancing medicine one research note at a time: the educational value in clinical case reports. BMC Res Notes 2012, 5:293.

16. Cases Database. [http://www.casesdatabase.com/]

17. Rison RA: A guide to writing case reports for the Journal of Medical Case Reports and BioMed Central Research Notes. J Med Case Reports 2013, 7:239.

18. CARE guidelines. [http://www.CARE-statement.org]

doi:10.1186/1752-1947-7-261

Cite this article as: Rison et al:: The CARE (CAse REport) guidelines and the standardization of case reports. Journal of Medical Case Reports 2013 7:261.

\section{Submit your next manuscript to BioMed Central and take full advantage of:}

- Convenient online submission

- Thorough peer review

- No space constraints or color figure charges

- Immediate publication on acceptance

- Inclusion in PubMed, CAS, Scopus and Google Scholar

- Research which is freely available for redistribution 